\title{
Spatial and temporal analysis of leopards (Panthera pardus), their prey and tigers (Panthera tigris) in Huai Kha Khaeng Wildlife Sanctuary, Thailand
}

\author{
Apinya Saisamorn ${ }^{1,2}$, Prateep Duengkae ${ }^{1 *}$, Anak Pattanavibool ${ }^{2}$, \\ Somphot Duangchantrasiri ${ }^{3}$, Achara Simcharoen ${ }^{4}$, James L.D. Smith ${ }^{5}$
}

${ }^{1}$ Special Research Unit for Wildlife Genomics, Department of Forest Biology, Faculty of Forestry,

Kasetsart University, Bangkok 10900, Thailand

${ }^{2}$ Wildlife Conservation Society, Thailand Program, 55/295 Muangthong Thani 5, Chaengwattana Road, Pakkred, Nonthaburi 10210, Thailand

${ }^{3}$ Department of National Parks, Wildlife and Plant Conservation, Paholyotin Road, Chatuchak, Bangkok 10110, Thailand

${ }^{4}$ Department of National Parks, Wildlife and Plant Conservation, Protected Area Regional Office 12, 19/47 Kositai

Road, Nakhonsawan, Thailand

${ }^{5}$ Department of Fisheries, Wildlife and Conservation Biology, University of Minnesota, 2003 Upper Buford Cr., St. Paul, MN 55108, USA

\begin{abstract}
Saisamorn, A., Duengkae, P., Pattanavibool, A., Duangchantrasiri, S., Simcharoen, A., Smith, J.L.D., 2019. Spatial and temporal analysis of leopards (Panthera pardus), their prey and tigers (Panthera tigris) in Huai Kha Khaeng Wildlife Sanctuary, Thailand. Folia Oecologica, 46: 73-82.

Despite their extensive distribution globally, recent reports indicate leopards are declining, especially in Southeast Asia. To support conservation efforts we analyzed the behavioral interactions between leopards (Panthera pardus), their prey, and tigers to determine if leopards fine-tune their activity to maximize contact with four prey species (sambar; wild boar; barking deer; banteng) and avoid tigers and if prey alter their temporal activity in response to variation in their relative abundance ratio with leopards. A lower density of sambar in the northern part of our study area and a lower density of wild boar and a higher density of tigers in the southern part allowed us to examine fine-grained differences in the behavior of leopards and their prey. We used camera trap data to investigate spatial and temporal overlap. Differences in tiger relative abundance did not appear to impact the temporal activity of leopards. Leopards had similar cathemeral activity at all sites with highest activity at dawn and dusk. This behavior appears to be a compromise to provide access to diurnal wild boar and barking deer and nocturnal sambar and banteng. Sambar showed higher temporal avoidance of leopards in the north where its RAI was lowest; in contrast, wild boar had the highest temporal avoidance in the south where its density was lowest. This is the first study in Southeast Asia to quantify spatial and temporal interactions between the leopard, its primary ungulate prey, and the tiger. It provides new insights for conserving this declining subspecies.
\end{abstract}

Keywords

leopard, prey, tiger, spatial activity, temporal activity

*Corresponding author:

e-mail: prateepd@hotmail.com 


\section{Introduction}

Leopards (Panthera pardus) have the widest species distribution among large felids; they are documented from southern Africa through the Middle East to South, Southeast and Northeast Asia (Miththapala et al., 1996; UpHYRKINA et al., 2001). Currently, eight subspecies are recognized (KITCHENER et al., 2017). However, leopards have experienced recent declines in distribution, and increasing reports describe population extirpation in many localities (STEIN et al., 2016). Causes of widespread decline, as also reported for tigers (Panthera tigris), are due to habitat loss, degradation and fragmentation, as well as poaching and prey depletion (STEIN et al., 2016). Here we focus on a population of Indochinese leopard (Panthera pardus delacouri), which is found in Southeast Asia and southern China. Rostro-García et al. (2016) report that this subspecies now occurs in only $6.2 \%$ of its historical range in Southeast Asia, and that only seven viable populations remain: three in Myanmar, one in Cambodia, one in Malaysia and two in Thailand.

Given the newly recognized concern regarding status of the leopard in Southeast Asia, knowledge of its behavioral interactions with its major prey, and with tigers, is critical for efforts to conserve this species. An earlier study on the ecology of leopards in Southeast Asia (SIMCHAROEN et al., 2018) was conducted in Huai Kha Khaeng Wildlife Sanctuary (HKK), Thailand, which supports the largest populations of leopards and tigers in the region (KenNey et al., 2014; Rostro-García et al., 2016). Recent studies of leopard and tiger diets report a high degree of dietary overlap at several sites in South Asia (LovARI, 2015; Selvan et al., 2013) and also at our study site in HKK (Simcharoen et al., 2018). Simcharoen and colleagues found that the species of highest biomass in the leopard's diet was sambar (Rusa unicolor) $(36 \%)$; other major species were wild boar (Sus scrofa) (16.5\%), barking deer (Muntiacus muntjak) (12.5\%) and banteng (Bos javanicus) (9.1\%). These four species composed $78 \%$ of the leopard's diet and are the focus of this study. Optimum foraging theory predicts that predators should alter their spatial and temporal activity to increase encounter rates with prey and where prey abundance varies spatially, they should show a local preference for the species with highest density (CHARNOV, 1976) or the highest probability of detection (Holling, 1959). In turn, prey often respond to predators by temporal and spatial avoidance, which has been characterized as the ecology of fear (BROwN et al., 1999). The fear response of prey species, however, must be balanced by the need to forage (CREEL et al., 2007).

The consequence of interactions between predator and prey result in predators adjusting their temporal and spatial activity to correlate with the activity of their prey (KARANTH and SUNQUist, 2000; LINKIE and RIDOUT, 2011). And in response, prey may alter their activity to avoid either temporal and/or spatial overlap with predators (KRONFELD-SCHOR and DAYAN, 2003). Given the leopard's diverse ungulate diet, it needs to adjust its spatial and temporal activities to maximize opportunities to capture all major prey despite the likelihood that activity patterns differ among species. Furthermore, in carnivore guilds, interference competition by larger carnivores impacts smaller carnivores, usually the next smaller species (DonADIO and Buskirk, 2006; PAlomares and CARO, 1999). Interference competition by tigers towards leopards is widely reported (KARANTH and SUNQUIST, 1995; Mondal et al., 2011; RAMAKRISHNAN et al., 1999; RAMESH et al., 2012; SCHALLER, 1967) and it results in lower leopard density in core areas used by tigers as leopards shift to peripheral habitat where larger prey preferred by tigers are less abundant. However, the degree of interference competition varies; at two sites in South Asia, Pakke Tiger Reserve, Arunachal Pradesh (SElvan et al., 2013) and the Western Ghats (Karanth et al., 2017; Karanth and SUNQUIST, 1995; KARANTH and SUNQUIST, 2000) high spatial overlap was reported in these felids. Karanth et al. (2017) suggested temporal partitioning facilitates co-occurrence by reducing the probability of leopards encountering tigers thus allowing leopards to spatially coexist with tigers.

High dietary overlap between leopards and tigers has also been reported and is referred to as resource competition (KARANTH et al., 2017). Resource competition between leopards and tigers may be more intense in Southeast Asia than in South Asia, in part because the most common prey species of leopards in South Asia, the medium sized spotted deer (Axis axis) (ANDHERIA et al., 2007; KARANTH and SunQuist, 1995; Mondal et al., 2011; SCHALler, 1967) is absent in Southeast Asia. Furthermore, in Southeast Asia, three other medium-size deer, comparable in size to the spotted deer, have been extirpated (LEKAGUL and MCNEELY, 1977) thus creating a gap in prey size for leopards between wild boar and sambar. This size gap may explain the leopard's reliance on young sambar as its major prey (SIMCHAROEN et al., 2018). The sambar is also the second most abundant prey species of tigers and the high dietary overlap indicates resource competition (Simcharoen et al., 2018). In this study, we examine the activity overlap of leopards and their prey and hypothesize that 1) leopards should adjust their activity to maximize contact with all of their major prey, 2) leopards should locally fine-tune their activity to favor overlap with the most abundant of these prey species, and prey in turn should show greatest avoidance of leopards when their density is lowest, and 3) leopards should adjust their temporal activity in response to higher tiger density where the probability of encounter with tigers is higher. Studying the temporal and spatial relationship of leopards and their major prey, and the potential impact of tigers on these dynamics, is critical to conservation of leopards.

\section{Materials and methods}

\section{Study site}

The study was conducted in Huai Kha Khaeng, a 2,780 $\mathrm{km}^{2}$ protected area, which is one of three protected areas designated as a World Heritage Site. It forms the core of 
a $\sim 19,000 \mathrm{~km}^{2}$ landscape, the Western Forest Complex (WEFCOM) of Thailand, which is the largest remaining contiguous protected area in mainland Southeast Asia. HKK is primarily composed of deciduous forest (83\%), dry dipterocarp forest (13\%), dry evergreen forest $(3 \%)$, and unknown (1\%) forest type (TRISURAT, 2004). The elevation in HKK ranges from 160 to $1,687 \mathrm{~m}$ above mean sea level. Annual average precipitation is $1,164 \mathrm{~mm}$ and the average temperature ranges from $7{ }^{\circ} \mathrm{C}$ to $31^{\circ} \mathrm{C}$.

\section{Data collection}

Camera trap data were collected during January-May in 2013 and 2015 as part of a long-term project to monitor large carnivores and their major prey: sambar, gaur, banteng, wild boar and barking deer. We set 203 camera trap stations covering an area of approximately 1,000 $\mathrm{km}^{2}$. These stations were established along animal trails, ridges and streams, and near saltlicks, to maximize image capturing opportunities of these species. The inter-trap distance was 3-4 km. A pair of cameras was installed at each station on trees about $50 \mathrm{~cm}$ above the ground (Fig. 1). At each trap site, cameras were deployed for 15 days following a protocol developed by DUANGCHANTRASIRI et al. (2016). Photographs from trap stations provided spatial and temporal data used for estimating spatial and temporal overlap among leopards, their prey and tigers. Images of the same species at a camera station were considered to be independent if they were: 1) non-consecutive images (e.g., taken after another species had been photographed), 2) consecutive images with a time interval between shots $>30 \mathrm{~min}$, or 3) consecutive images in which each animal could be individually identified (e.g., different sex or age class) (O'Brien et al., 2003; RAMESH et al., 2012; YASUDA, 2004). These data were used to analyze the activity of leopards and their prey. We also calculated the relative abundance index (RAI) of leopards, tigers and the leopard's 4 major prey species as the total number of photographs per 100 trap nights (ANTONY et al., 2013; CARBONE et al., 2001). The RAI ratio of prey and tiger to leopard RAI was used to determine if spatial or temporal overlap of prey was influenced by differences in the relative abundance ratio of prey or tigers to leopards among sites. RAI, a presence only statistic, is often criticized because bias in detection among species varies (SolLmanN et al., 2013); however, given the same general habitat characteristics across our study area, the between species bias of RAI should not vary among different parts of our study area and thus the ratio of leopard RAI to the RAI of each prey species, and to tigers, provides a reasonable index to compare relative abundance differences across sites within HKK.

\section{Data analysis}

We analyzed data across all camera trap sites and at two subsamples, Khao Nang Rum (KNR) in the northern and Khao Ban Dai (KBD) in the southern part of our study site. These subsamples had different relative abundances of sambar, wild boar and tigers and thus provided a comparison of ecological factors influencing activity patterns. Temporal activity was measured as the number of photographs of each species obtained during each hour of the day. We then characterize temporal activity as the percentage of time an animal was diurnal (i.e. active 0600-1859) (VAN SCHAIK and GRIFFITHS, 1996). Diurnal activity was classified as strongly diurnal ( $\geq 85 \%$ ), mostly diurnal (61$84 \%$ ), cathemeral (40-60\%), mostly nocturnal (39-16\%) and strongly nocturnal $(\leq 15 \%)$. We then compared these general differences in diurnal activity between the leopard and each of its four major ungulate prey species.

For a more fine grained estimate of temporal overlap we measured the extent of overlap in activity between leopards and prey using the kernel density package in $\mathrm{R}$ to determine the coefficient of overlapping $(\Delta)$, which ranged from 0 (no overlap) to 1 (complete overlap) (Ridout and Linkie, 2009). Overlap was defined as the area under the curve expressed by taking the minimum of two kernel density estimates at each time point. As recommended by Ridout and Linkie (2009), we used their $\Delta_{4}$ method for large sample size to estimate the probability density function of overlap.

We also calculated both temporal and spatial Spearman rank correlation coefficients (AZLAN and SHARMA, 2006; RAMESH et al., 2012) performed in R software ( $R$ Core Team, 2017) to determine if leopards and their major prey have either spatial or temporal differences in overlap among sites with different prey densities.

\section{Results}

Using 203 trap stations (6,225 trap nights) we obtained independent images of 324 leopards, 981 sambar, 682 wild boar, 1,169 barking deer, 137 banteng and 276 tiger. The RAI of leopards ranged from 5.2 over all sites to a high of 6.2 in the south and 5.6 in the north (Table 1). For sambar the RAI was 18.5 at KBD (south) or 2.4 times higher than at KNR (north) 7.8. This difference in relative abundance of sambar resulted in a sambar to leopard RAI ratio $\sim 2 \times$ higher at KBD compared to KNR (Table 1). In contrast the RAI of wild boar was 15.3 at KNR or 1.7 times higher at KNR than at KBD and the leopard wild boar ratio was $\sim 2 \times$ higher in KNR compared to KBD. Barking deer had similar RAI for all 3 sites (15.4 at KNR to 18.2 at KBD and 18.8 over all sites). The ratio of barking deer to leopard RAI was highest among the prey species we examined, but very similar at KBD and KNR, and the ratio for banteng to leopard was similar across all sites (Table 1).

\section{Behavioral responses between leopards and their prey}

\section{Sambar}

Spearman spatial correlation between leopards and sambar was significantly correlated overall $(p<0.05)$ and highly correlated at $\mathrm{KBD}(\mathrm{p}=0.07)$ (Table 2$)$, and was 


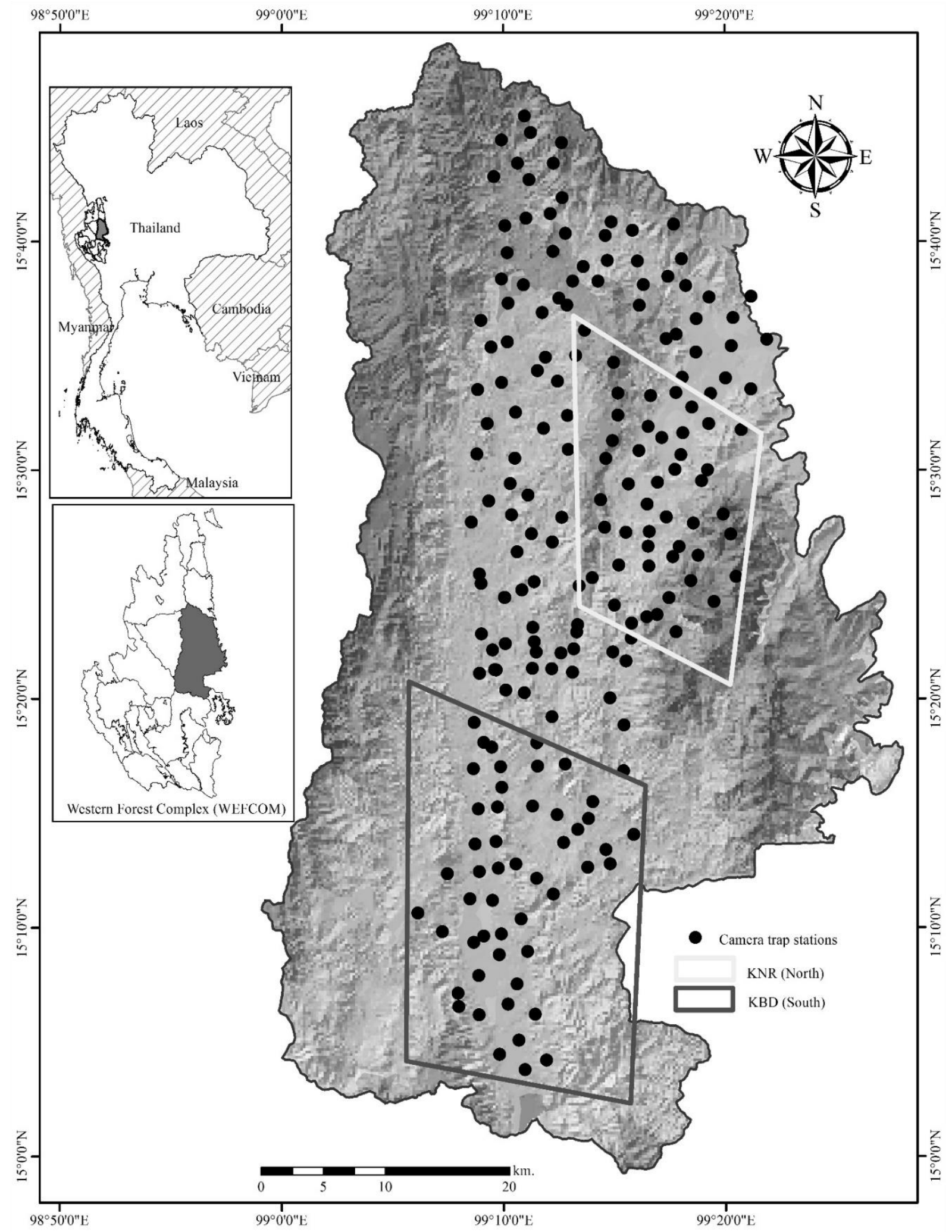

Fig. 1. Camera trap stations in Huai Kha Khaeng Wildlife Sanctuary (HKK) during January-May in 2013 and 2015. 
lowest at KNR where sambar relative abundance was lowest (Table 1). Sambar also had the highest temporal separation at KNR where it was strongly nocturnal (89\%) versus the leopard's cathemeral (54\% diurnal) behavior. Further evidence of stronger avoidance by sambar at low density sites was low temporal kernel overlap between leopards and sambar at $\mathrm{KNR}\left(\Delta_{4}=0.62\right)$ (Fig. 2). At KBD where sambar density was double that at KNR, kernel overlap was higher $\left(\Delta_{4}=0.83\right)$ and both sambar and leopards were cathemeral.

\section{Wild boar}

Wild boar had variable Spearman spatial overlap. It was significant across the entire study area, but not significant at the KNR (northern sub-site) or KBD (southern sub-site) (Table 2); Spearman temporal correlation was also variable across sites. It was least significant at $\operatorname{KBD}(p=0.80)$ and the kernel spatial density overlap was also lowest at $\operatorname{KBD}\left(\Delta_{4}=0.61\right)$ (Fig. 2$)$ where its RAI and the leopard and wild boar RAI ratio was lowest. Also at KBD the wild boar was strongly diurnal $(90 \%)$, which resulted in the strongest avoidance of cathemeral leopards (53\%). In contrast, at KNR, the cathemeral leopard and the mostly diurnal wild boar had the highest kernel temporal overlap estimate $\left(\Delta_{4}=0.78\right)$ (Table 3, Fig. 2).

\section{Barking deer}

There was no significant Spearman spatial overlap among the three sites and temporal overlap was only significant at the combined sites, but not at either the northern or southern sites. Among the three sites, diurnal activity ranged from $65-77 \%$, which resulted in the closest temporal overlap among the three prey species to the cathemeral leopard (53-55\% diurnal). The temporal kernel overlap was higher overall at KNR and lower at KBD. Both barking deer and leopards showed bimodal peak activity levels after dawn and before dusk at all sites. However, among the 4 prey species, the spatial correlation of leopard and barking deer was lowest and in fact, it was negative at both KNR and KBD.

\section{Banteng}

Spearman spatial correlation was not significant at the northern and southern sites, but nearly significant overall $(\mathrm{p}=0.06)$ among the combined sites; there was no Spearman temporal overlap at any of the sites (Table 3). Banteng temporal activity ranged from nocturnal at the combined sites, nocturnal at KNR but, although the temporal kernel overlap between leopards and banteng was lowest at KBD $\left(\Delta_{4}=0.62\right)$, with only 24 photos (14 diurnal and 10 nocturnal at KBD) we draw no conclusions about the dynamics between leopard and banteng at this site.

In summary, the leopard's cathemeral temporal activity pattern appears to be a compromise that provides access to the more nocturnal sambar and the more diurnal wild boar and barking deer. Both sambar and wild boar showed the strongest temporal avoidance of leopards at the site where each of these species occurred at the low- 
est density. Elsewhere they have a broader activity period. Barking deer had the highest temporal overlap with leopards, but the lowest spatial overlap. The pattern for banteng was less clear because of low sample size at KBD.

\section{The impact of tigers on leopards}

Tiger density did not appear to impact either the density or temporal activity of leopards. Leopard RAI was similar ranging from 5.2 for all sites, 5.6 at $\mathrm{KNR}$ and 6.2 at $\mathrm{KBD}$ despite the estimate that tiger RAI was $3 \times$ greater at KBD compared to KNR. Leopard temporal activity also was not impacted by the difference in tiger density. Its pattern was cathemeral at all three sites (diurnal activity ranged from $53-55 \%$ ) (Table 3). We have no temporal activity data for tigers from 2013 and 2015.

\section{Discussion}

This is the first study in mainland Southeast Asia that quantifies spatial and temporal interactions between the leopard, the region's second largest felid, and its primary ungulate prey. It also examined the temporal activity pattern of leopards to determine if it was impacted by tiger density. Although the leopard has a diverse diet of approximately 20 species, $74.2 \%$ of its diet consists of a combination of six species medium size adult and young of large size ungulates (Simcharoen et al., 2018). These prey are especially critical food resources for female leopards, who continue to provide food for their young prior to dispersal (Simcharoen et al., 2007, 2008). Because the density of sambar, wild boar, banteng, and tiger varied across our study area, we examined two subsets of data. One was at KNR where wild boar relative density was high compared to the relative density of sambar and the other was at KBD where the relative density of sambar was high compared to the relative density of wild boar. We also examine if there were differences in leopard activity between KBD and KNR in response to tigers having a RAI nearly 3 times higher at KBD compared to KNR.

Overall, leopards exhibited the highest activity at or just after dawn and before or at dusk. This cathemeral activity pattern was very similar to that found in Northeast China (YANG et al., 2018). It may be a strategy that maximizes encounters with the more diurnal wild boar and barking deer as well as the nocturnal sambar. The extent to which leopards or banteng adjust their behavior in response to each other is unknown because our sample size of banteng at KBD was small. Occasionally leopards have been observed feeding on banteng killed by tigers, but diet data from HKK indicates that $70 \%$ of banteng remains in the diet of leopards are from young (Simcharoen et al., 2018). Additionally, a tiger is not likely to abandon or allow a leopard to obtain much meat from a small banteng kill. Therefore, it is unlikely that these scats were produced from foraging on tiger kills. In summary, each of these four species are important components of the leopard's diet and demonstrate a strategy of maximizing energy intake.

The spatial and temporal overlap of the leopard with its two primary prey species, sambar and wild boar, varied across sites suggesting that the leopard may shift its activity to focus on its most abundant prey species. BROWN

Table 2. Spearman spatial and temporal rank correlation of leopard activity in relation to four major prey in HKK

\begin{tabular}{|c|c|c|c|c|}
\hline \multirow{2}{*}{ Variables } & \multicolumn{2}{|c|}{ Spatial } & \multicolumn{2}{|c|}{ Temporal } \\
\hline & Spearman correlation & p-value & Spearman correlation & $\mathrm{p}$-value \\
\hline \multicolumn{5}{|l|}{ All } \\
\hline Leopard and sambar & $* 0.26$ & $<0.05$ & 0.19 & 0.37 \\
\hline Leopard and wild boar & $* 0.24$ & $<0.05$ & 0.29 & 0.16 \\
\hline Leopard and barking deer & 0.04 & 0.57 & $* 0.48$ & $<0.05$ \\
\hline Leopard and banteng & 0.13 & 0.06 & 0.15 & 0.50 \\
\hline \multicolumn{5}{|l|}{ KNR (North) } \\
\hline Leopard and sambar & 0.19 & 0.21 & -0.15 & 0.49 \\
\hline Leopard and wild boar & 0.05 & 0.74 & 0.38 & 0.07 \\
\hline Leopard and barking deer & -0.12 & 0.42 & 0.22 & 0.30 \\
\hline Leopard and banteng & 0.19 & 0.19 & -0.02 & 0.91 \\
\hline \multicolumn{5}{|l|}{ KBD (South) } \\
\hline Leopard and sambar & 0.26 & 0.07 & 0.13 & 0.53 \\
\hline Leopard and wild boar & -0.02 & 0.90 & 0.06 & 0.80 \\
\hline Leopard and barking deer & -0.11 & 0.44 & 0.05 & 0.82 \\
\hline Leopard and banteng & -0.01 & 0.94 & -0.03 & 0.90 \\
\hline
\end{tabular}

$*$ p-value $<0.05$ 

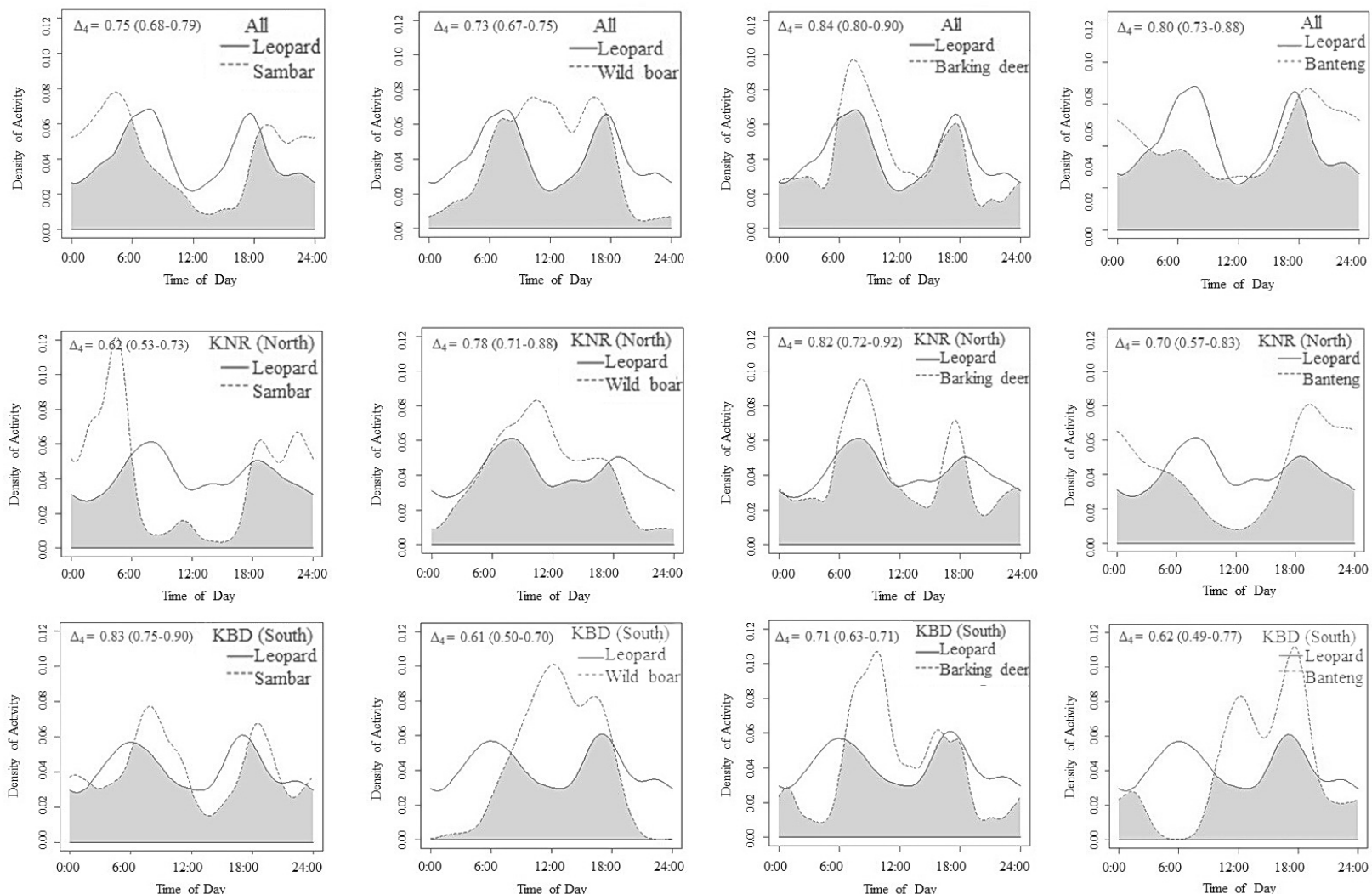

Fig. 2. Estimate of daily activity pattern of leopards and four major prey for all camera trap sites (row 1), northern subset of camera sites at KNR (row 2) and southern subset of camera trap sites at KBD (row 3).

Table 3. The daily activity of species was classified based on the percentage of diurnal activity (06:00-17:59): strongly diurnal ( $\geq 85 \%)$, mostly diurnal (84-61\%), cathemeral (60-40\%), mostly nocturnal (39-16\%) and strongly nocturnal $(\leq 15 \%)$

\begin{tabular}{ccccccc}
\hline Site & Time & Leopard & Sambar & Wild boar & Barking deer & Banteng \\
\hline All & $06: 00-17: 59$ & $176(54 \%)$ & $270(28 \%)$ & $547(80 \%)$ & $803(69 \%)$ & $50(36 \%)$ \\
& $18: 00-05: 59$ & $148(46 \%)$ & $711(72 \%)$ & $135(20 \%)$ & $366(31 \%)$ & $87(64 \%)$ \\
& & Cathemeral & $\begin{array}{c}\text { Mostly } \\
\text { nocturnal }\end{array}$ & Mostly diurnal & Mostly diurnal & $\begin{array}{c}\text { Mostly } \\
\text { nocturnal }\end{array}$ \\
& & & & & $9(20 \%)$ \\
KNR (North) & $06: 00-17: 59$ & $54(55 \%)$ & $15(11 \%)$ & $199(75 \%)$ & $175(65 \%)$ & $95(80 \%)$ \\
& $18: 00-05: 59$ & $44(45 \%)$ & $121(89 \%)$ & $68(25 \%)$ & $93(36 \%)$ & Mostly \\
& & Cathemeral & Strongly & Mostly diurnal & Mostly diurnal & \\
KBD (South) & $06: 00-17: 59$ & $49(53 \%)$ & $142(51 \%)$ & $107(90 \%)$ & $208(77 \%)$ & $14(58 \%)$ \\
& $18: 00-05: 59$ & $43(47 \%)$ & $134(49 \%)$ & $13(10 \%)$ & $62(23 \%)$ & $10(42 \%)$ \\
& & Cathemeral & Cathemeral & Strongly diurnal & Mostly diurnal & Cathemeral \\
\hline
\end{tabular}

et al. (1999) and GARROTT et al. (2007) found similar prey switching in wolves. GARROTT et al. (2007), also noted that prey in turn modify their temporal behavior in response to changing predation risk. Both sambar and wild boar avoidance behavior was stronger when these species occurred at lower density because the probability of an individual sambar or wild boar encountering a leopard is lower where there are more prey individuals per leopard. Thus, based strictly on the probability of encounter (HoLLING, 1959), we expected and found that sambar and wild boar had the strongest tem- poral avoidance where their density was lowest. In KNR the leopard sambar RAI was half the ratio at KBD and the temporal overlap was $\Delta_{4}=0.62$ compared to an overlap of 0.83 at KBD. We found a similar but geographically reverse pattern for wild boar. At KNR the RAI ratio of leopard to wild boar was $\sim$ half the ratio at KBD and the $\Delta_{4}=0.61$ versus a $\Delta_{4}=0.78$. Thus, our data support the second hypothesis that predators locally fine-tune their activity to favor overlap with the most abundant of these prey species and prey avoid overlap with predators where their density is lowest. 
Our third hypothesis that leopards should adjust their activity to have less overlap with tigers where tiger RAI was highest was rejected. The tiger RAI at KBD was $3 \times$ the RAI at KNR and female tiger home range size at KBD was reported to be $\sim 31 \mathrm{~km}^{2}$ versus a home range size at KNR of $\sim 62 \mathrm{~km}^{2}$ (Simcharoen et al., 2014). Together these data suggest the density of tigers at KBD was at least double the density at KNR, but leopards did not adjust their cathemeral activity pattern in response to tiger home range size or RAI. Lack of evidence of effective interference competition by tigers toward leopards at HKK is interesting, because it is widely reported to occur in South Asia (Odden et al., 2010; Harihar et al., 2011; Steinmetz et al., 2013). However, KARANTH et al. (2017) also reported lack of interference competition in Southwest India. HoLLING (1959) modeled predation success as consisting of encounter rate and capture success. Simcharoen et al. (2018) suggest that low encounter rate as a consequence of dense cover might also explain the lack of evidence of interference competition. MAPUTLA et al. (2015) also found that leopard prey selection was more important than the influence of lion movement patterns in South Africa. Despite the large number of documented cases of interference competition, modern statistical modeling emphasizes that different ecological correlates should result in different predictions so it should not be surprising that the degree of interference competition varies across the leopard's range.

Given that both leopards and tigers are threatened across Southeast Asia and that their largest populations occur in WEFCOM, research at HKK contributes to the understanding of interspecies dynamics between these two large felids. There is no clear evidence of tigers reducing the density of leopards or altering activities in HKK, but in response to widespread interference competition by tigers toward leopards elsewhere, and the increasing decline of leopards in Southeast Asia (Rostro-García et al., 2016), managers need a conservation strategy that encompasses threats to both species. Unfortunately, rigorous field studies on the behavioral dynamics of carnivores and their prey are exceedingly difficult (GARROTT et al., 2007) and the difficulty is compounded where two large predators with overlapping diets occur. HKK has a history of long-term research on tigers and leopards and is an ideal site for more intensive behavioral studies which are needed to drive scientific management of these co-occurring species.

\section{Acknowledgements}

We thank the Wildlife Conservation Society for supporting our research and we are grateful to the Liz Claiborne and Art Ortenberg Foundation and Department of National Parks, Wildlife and Plant Conservation for funding support. We acknowledge the staff of Khao Nang Ram Research Station for their many contributions in the field. Prateep Duengkae is the recipient of "Wildlife habitat restoration for prey species of tiger in Dong Phayayen-Khao Yai Forest Complex" (P-18-51249) Research Grant, the
National Science and Technology Development Agency (NSTDA), Thailand and J.L.D. Smith's contribution to this research was supported by the USDA National Institute of Food and Agriculture.

\section{References}

Andheria, A.P., Karanth, K.U., Kumar, N.S., 2007. Diet and prey profiles of three sympatric large carnivores in Bandipur Tiger Reserve, India. Journal of Zoology, 273 (2): 169-175. https://doi.org/10.1111/j.14697998.2007.00310.x

Azlan, J.M., Sharma, D.S.K., 2006. The diversity and activity patterns of wild fields in a secondary forest. Oryx, 40 (1): 36-41. https://doi.org/10.1017/S0030605306000147

Brown, J.S., Laundre, J.W., Gurung, M., 1999. The ecology of fear: optimal foraging, game theory, and trophic interactions. Journal of Mammalogy, 80 (2): 385-399. https://doi.org/10.2307/1383287

Carbone, C., Christie, S., Conforti, K., Coulson, T., Franklin, N., Ginsberg, J.R., Griffiths, M., Holden, J., KaWANishi, K., KinNaird, M.F., LAidlaW, R., Lynam, A., Macdonald, D., Martyr, D., McDougal, C., Nath, L., O’Brien, T.G., Seidensticker, J., Smith, D.J.L., Sunquist, M.E., Tilson, R., Shahruddin, W.N.W., 2001. The use of photographic rates to estimate densities of tigers and other cryptic mammals. Animal Conservation, 4: 75-79.

Charnov, E.L., 1976. Optimum foraging and the marginal value theorem. Theoretical Population Biology, 9: 129136.

Creel, S., Christianson, D., Liley, S., Winnie, J.A., 2007. Predation risk affects reproductive physiology and demography of elk. Science, 315 (5814): 960.

Donadio, E., Buskirk, S.W., 2006. Diet, morphology, and interspecific killing in carnivora. The American Naturalist, 167 (4): 524-536. doi: 10.1086/501033

Duangchantrasiri, S., Umponjan, M., Simcharoen, S., Pattanavibool, A., Chaimattana, S., Maneerat, S., Kumar, N.S., Jathanna, D., Srivathsa, A., Karanth, K.U., 2016. Dynamics of a low-density tiger population in Southeast Asia in the context of improved law enforcement. Conservation Biology, 30 (3): 639-648. https://doi. org/10.1111/cobi.12655

Garrott, R.A., Bruggeman, J.E., Becker, M.S., KalinOWSKI, S.T., WhITE, P.J., 2007. Evaluating prey switching in wolf-ungulate systems. Ecological Applications, 17 (6): 1588-1597. doi: 10.1890/06-1439.1

Harihar, A., Pandav, B., Goyal, S.P., 2011. Responses of leopard Panthera pardus to the recovery of a tiger Panthera tigris population. Journal of Applied Ecology, 48 (3): 806-814. https://doi.org/ 10.1111/j.13652664.2011.01981.x

Holling, C.S., 1959. Some characteristics of simple types of predation and parasitism. The Canadian Entomologist, 91 (7): 385-398. https://doi.org/10.4039/Ent91385-7

Karanth, K. U., Srivathsa, A., Vasudev, D., Puri, M., Parameshwaran, R., Kumar, N.S., 2017. Spatio-temporal interactions facilitate large carnivore sympatry across 
a resource gradient. Proceedings of the the Royal Society. Biological Sciences, 284 (1848): 20161860. https://doi. org/10.1098/rspb.2016.1860

Karanth, K.U., Sunquist, M.E., 1995. Prey selection by tiger, leopard and dhole in tropical forests. The Journal of Animal Ecology, 64 (4): 439-450. doi: 10.2307/5647

Karanth, K.U., Sunquist, M.E., 2000. Behavioural correlates of predation by tiger (Panthera tigris), leopard (Panthera pardus) and dhole (Cuon alpinus) in Nagarahole, India. The Zoological Society of London, 250: 255-265. https://doi.org/10.1111/j.1469-7998.2000.tb01076.x

Kenney, J., Allendorf, F.W., McDougal, C., Smith, J.L., 2014. How much gene flow is needed to avoid inbreeding depression in wild tiger populations? Proceedings of the Royal Society B. Biological Sciences, 281 (1789): 20133337. https://doi.org/10.1098/rspb.2013.3337

Kitchener, A.C., Breitenmoser-Würsten, Ch., Eizirik, E., Gentry, A., Werdelin, L., Wilting, A., YamaguChi, N., Abramov, A.V., Christiansen, P., Driscoll, C., Duckworth, J.W., Johnson, W., Luo. S.-J., Meijaard, E., O’Donoghue, P., Sanderson, J., Seymour K., Bruford, M., Groves, C., Hoffmann, M., Nowell, K., TimMONS, Z., Tobe, S., 2017. A revised taxonomy of the Felidae. The final report of the Cat Classification Task Force of the IUCN/SSC Cat Specialist Group. Cat News Special Issue, 11: 80 .

Kronfeld-Schor, N., Dayan, T., 2003. Partitioning of time as an ecological resource. Annual Review of Ecology, Evolution, and Systematics, 34 (1): 153-181. https://doi. org/10.1146/annurev.ecolsys.34.011802.132435

Lekagul, B., McNeely, J.A., 1977. Mammals of Thailand. Bangkok: Kurusapha Ladpao Press. 758 p.

Linkie, M., Ridout, M.S., 2011. Assessing tiger-prey interactions in Sumatran rainforests. Journal of Zoology, 284 (3): 224-229. https://doi.org/10.1111/j.14697998.2011.00801.x

Lovari, S., Pokheral, C.P., Jnawali, S.R., Fusani, L., FerRETTI, F., 2015. Coexistence of the tiger and the common leopard in a prey-rich are: the role of prey partitioning. Journal of Zoology, 295: 122-131.

Lynam, J.A., Jenks, E.K., Tantipisanuh, N., Chutipong, W., Ngoprasert, D., Gale, A.G., Steinmetz, R., SukMASUANG, R., BhumpaKPHAN, N., Lon, I., Grassman, J., Kitamura, S., Reed, H.D., Baker, C.M., McShea, W., Songsasen, N., Leimgruber, P. 2013. Terrestrial activity patterns of wild cats from camera-trapping. The Raffles Bulletin of Zoology, 61 (1): 407-415.

Maputla, N.W., Maruping, N.T., Chimimba, C.T., FerREIRA, S.M., 2015. Spatio-temporal separation between lions and leopards in the Kruger National Park and the Timbavati Private Nature Reserve, South Africa. Global Ecology and Conservation, 3: 693-706. https://doi.org. 10.1016/j.gecco.2015.03.001

Miththapala, S., Seidensticker, J., O’Brien, S.J., 1996. Phylogeographic subspecies recognition in leopards (Panthera pardus): molecular genetic variation. Conservation Biology, 10: 1115-1132.

Mondal, K., Gupta, S., Qureshi, Q., Sankar, K., 2011. Prey selection and food habits of leopard (Panthera pardus fusca) in Sariska Tiger Reserve, Rajasthan, India. Mammalia, 75 (2): 201-205. https://doi.org/10.1515/ mamm.2011.011
O’Brien, T.G., Kinnaird, M.F., Wibisono, H.T., 2003. Crouching tigers, hidden prey: Sumatran tiger and prey populations in a tropical forest landscape. Animal Conservation, 6 (2): 131-139. https://doi.org/10.1017/ s1367943003003172

Odden, M., Wegge, P., Fredriksen, T., 2010. Do tigers displace leopards? If so, why? Ecological Research, 25 (4): 875-881. doi: 10.1007/s11284-010-0723-1

Palomares, F., CARo, T.M., 1999. Interspecific killing among mammalian carnivores. The American Naturalist, 153 (5): 492-508. doi: 10.1086/303189

R Core Team. 2017. R: a language and environment for statistical computing. Vienna, Austria: Foundation for Statistical Computing. https://www.r-project.org/

Ramakrishnan, U., Coss, R.G., Pelkey, N.W., 1999. Tiger decline caused by the reduction of large ungulate prey: evidence from a study of leopard diets in southern India. Biological Conservation, 89 (2): 113-120. https://doi. org/10.1016/s0006-3207(98)00159-1

Ramesh, T., Kalle, R., Sankar, K., Qureshi, Q., Bennett, N., 2012. Spatio-temporal partitioning among large carnivores in relation to major prey species in Western Ghats. Journal of Zoology, 287 (4): 269-275. https://doi. org.10.1111/j.1469-7998.2012.00908.x

Ridout, M.S.., LiNKIE, M., 2009. Estimating overlap of daily activity patterns from camera trap data. Journal of Agricultural, Biological, and Environmental Statistics, 14 (3): 322-337. https://doi.org/10.1198/jabes.2009.08038

Ripple, W.J., Estes, J.A., Beschta, R.L., Wilmers, C.C., Ritchie, E.G., Hebblewhite, M., Berger, J., Elmhagen, B., Letnic, M., Nelson, M.P., Schmitz, O.J., Smith, D.W., Wallach, A.D., Wirsing, A.J., 2014. Status and ecological effects of the world's largest carnivores. Science, 343 (6167): 1241484. doi: 10.1126/science. 1241484

Rostro-García, S., Kamler, J.F., Ash, E., Clements, G.R., Gibson, L., Lynam, A.J., McEwing, R., NAing, H., PAGLIA, S., 2016. Endangered leopards: range collapse of the Indochinese leopard (Panthera pardus delacouri) in Southeast Asia. Biological Conservation, 201: 293-300. https://doi.org/10.1016/j.biocon.2016.07.001

Schaller, G.B., 1967. The deer and the tiger. Chicago: The University of Chicago Press. 370 p.

Selvan, K.M., Veeraswami, G.G., Lyngdoh, S., Habib, B., Hussain, S.A., 2013. Prey selection and food habits of three sympatric large carnivores in a tropical lowland forest of the Eastern Himalayan Biodiversity Hotspot. Mammalian Biology - Zeitschrift für Säugetierkunde, 78 (4): 296-303. https://doi.org/10.1016/j.mambio.2012.11.009

Simcharoen, A., Savini, T., Gale, G.A., Simcharoen, S., Duangchantrasiri, S., Pakpien, S., Smith, J.L.D., 2014. Female tiger Panthera tigris home range size and prey abundance: important metrics for management. Oryx, 48 (3): 370-377. https://doi.org/10.1017/ s0030605312001408

Simcharoen, A., Simcharoen, S., Duangchantrasiri, S., Bump, J., Sмith, J.L.D., 2018. Tiger and leopard diets in western Thailand: Evidence for overlap and potential consequences. Food Webs, 15: e00085. https://doi. org/10.1016/j.fooweb.2018.e00085

Simcharoen, S., 2007. The relationship between environ- 
mental factors and leopards in Huai Kha Khaeng Wildlife Sanctuary Uthai Thani. Journal of Wildlife in Thailand, 14: 65-79.

Simcharoen, S., Barlow, A.C.D., Simcharoen, A., Smith, J. L.D., 2008. Home range size and daytime habitat selection of leopards in Huai Kha Khaeng Wildlife Sanctuary, Thailand. Biological Conservation, 141 (9): 2242-2250. https://doi.org/10.1016/j.biocon.2008.06.015

Sollmann, R., Mohamed, A., Samejima, H., Wilting, A., 2013. Risky business or simple solution - relative abundance indices from camera-trapping. Biological Conservation, 159: 405-412. https://doi.org/10.1016/j.biocon.2012.12.025

Stein, A.B., Athreya, V., Gerngross, P., Balme, G., Henschel, P., Karanth, U., Miquelle, D., Rostro, S., Kamler, J.F., Laguardia, A., 2016. Panthera pardus. The IUCN Red List of Threatened Species 2016: e.T15954A50659089. [cit. 2019-05-3]. http://dx.doi.org/10.2305/IUCN.UK.2016-1.RLTS. T15954A50659089.en

Steinmetz, R., Seuaturien, N., Chutipong, W., 2013. Tigers, leopards, and dholes in a half-empty forest: assessing species interactions in a guild of threatened carnivores. Biological Conservation, 163: 68-78. https:/doi. org/10.1016/j.biocon.2012.12.016

TRISURAT, Y., 2004. GIS database and its applications for ecosystem management. The Western Forest Complex Ecosystem Management Project, Department of National Park, Wildlife, and Plant Conservation, Bangkok, Thailand. $228 \mathrm{p}$.

Uphyrkina, O., Johnson, W.E., Quigley, H., Miquelle, D., Marker, L.L., Bushs, M., O’Brien, S. J., 2001. Phylogenetics, genome diversity and origin of moder leopard, Panthera pardus. Molecular Ecology, 10: 2617-2633.

Van Schaik, C. P., Griffiths, M., 1996. Activity periods of Indonesian rain forest mammals. Biotropica, 28 (1): 105112. doi: $10.2307 / 2388775$

Yang, H., ZhaO, X., Han, B., Wang, T., Mou, P., Ge, J., FenG, L., 2018. Spatiotemporal patterns of Amur leopards in northeast China: influence of tigers, prey, and humans. Mammalian Biology, 92: 120-128. https://doi. org/10.1016/j.mambio.2018.03.009

YASUDA, M., 2004. Monitoring diversity and abundance of mammals with camera traps: a case study on Mount Tsukuba, central Japan. Mammal Study, 29 (1): 37-46.

Received July 13, 2019

Accepted October 2, 2019 